\title{
Influence of Environment on Airborne Spore Concentrations and Severity of Asparagus Purple Spot
}

\author{
L. L. Granke and M. K. Hausbeck, Department of Plant Pathology, Michigan State University, East Lansing 48824
}

\begin{abstract}
Granke, L. L., and Hausbeck, M. K. 2010. Influence of environment on airborne spore concentrations and severity of asparagus purple spot. Plant Dis. 94:843-850.

Environmental conditions, airborne concentrations of Pleospora herbarum ascospores and conidia, and purple spot disease severity on spears and fern were monitored for 3 years in two notill asparagus fields in Michigan. Purple spot lesion development on spears was correlated with low temperature and vapor pressure deficit and high rainfall. Low vapor pressure deficit and high rainfall were also correlated with airborne ascospore concentrations at both sites. Lesion development on the fern was favored by longer periods of leaf wetness and low vapor pressure deficit and rainfall. Daily airborne conidia concentrations were positively correlated with average temperature and the number of hours of leaf wetness per day and negatively correlated with vapor pressure deficit. Airborne conidia concentrations displayed a diurnal periodicity with greater concentrations between 700 and $1300 \mathrm{~h}$. The results of this study indicate that a model to predict purple spot on asparagus spears should include temperature, vapor pressure deficit, and rainfall; a model for disease on the fern should include temperature, leaf wetness, vapor pressure deficit, and rainfall.
\end{abstract}

Purple spot of asparagus (Asparagus officinalis L.), caused by Pleospora herbarum (Pers.:Fr.) Rabenh. (anamorph Stemphylium vesicarium (Wallr.) Simmons), is an important fungal disease in many growing regions including Michigan (21), California (10), Washington (14), England (10), and New Zealand (9). The fungus overwinters as pseudothecia on the surface of asparagus fern debris $(9,12)$ and releases ascospores as primary inoculum in the spring $(8,10)$. The conversion to no-till asparagus production, where dried fern residue is left on the soil surface, has been implicated in the increase in purple spot from an occasional to an annual disease in Michigan $(11,16)$. While no-till production reduces wind erosion and enhances the quality of harvested spears (16), previous research showed that incorporating debris into soil reduced available primary inoculum and subsequent purple spot disease severity (13). However, tillage equipment used to bury plant debris may damage the crowns, which may exacerbate Phytophthora and Fusarium root rots (29).

In the spring, the forcible discharge of $P$. herbarum ascospores follows wetting of mature pseudothecia $(2,12)$, and the pathogen enters the host via open stomata and wounds $(10,15)$. Purplish lesions may

Corresponding author: M. K. Hausbeck

E-mail: hausbec1@msu.edu

Accepted for publication 21 March 2010.

doi:10.1094/PDIS-94-7-0843

(C) 2010 The American Phytopathological Society subsequently develop on the spears, making them commercially unacceptable (13), especially for the fresh market. Once disease develops on asparagus spears, conidia may be released from lesions with the sporulating pathogen, which may subsequently infect additional spears or the main stems and secondary branches and cladophylls of ferns. Following infection, tan to brown lesions may develop on the fern and premature defoliation may occur $(7,21)$. Premature defoliation of the fern limits its photosynthetic ability, resulting in decreased carbohydrate reserves for the crown (11) that may negatively affect yields in following years.

Currently, purple spot of asparagus is managed by using cover crops to reduce abrasion and wounding of spears via windblown sand, and by applying fungicides. Growers apply fungicides to manage purple spot on the fern after the last spears are harvested; fungicides are not applied to asparagus spears that will be harvested (web1.msue.msu.edu/vegetable/Resources/ AsparagusPurpleSpot.pdf). Currently, protectant fungicides containing mancozeb, chlorothalonil, or azoxystrobin, a reduced risk product, are registered for use on asparagus. The forecasting model TOMCAST (Tomato disease forecasting) is used to time foliar fungicide sprays to protect asparagus fern in most commercial asparagus production systems in Michigan (web1.msue.msu.edu/vegetable/Resources/ AsparagusPurpleSpot.pdf). TOM-CAST (25) uses leaf wetness duration and average temperature during periods of leaf wetness to generate disease severity values, which prompt foliar fungicide applications to asparagus ferns. Previous studies showed that TOM-CAST-guided sprays of chlorothalonil resulted in satisfactory disease control and reduced the number of fungicide applications as compared to a calendar-based spray program, but TOM-CAST was not useful for timing mancozeb applications $(11,21)$. FAST (Forecasting system for Alternaria solani on tomato), the forecasting system from which TOM-CAST was derived, includes rainfall in addition to the factors included in TOM-CAST (18). FAST is used to predict Alternaria solani spore formation and infection of tomato and is utilized to guide fungicide applications to control early blight of tomato caused by $A$. solani, a fungus closely related to $P$. herbarum (28). FAST has also been adapted to prompt fungicide applications to control brown spot of pear caused by Stemphylium vesicarium (23).

Purple spot severity on asparagus spears and ferns was previously observed to be associated with the concentration of $P$. herbarum ascospores and conidia in the air (12), but the statistical significance of this relationship was not investigated. Another previous study indicated that purple spot on asparagus spears in the field was more severe following rainfall or overhead irrigation (10), and increased disease levels were observed on inoculated asparagus plants kept in a mist chamber for longer periods of time in a greenhouse study (15). Purple spot was most severe on inoculated asparagus ferns that were incubated under conditions of low light, high relative humidity, and high temperatures, and older ferns were less susceptible to infection in a study by Menzies et al. (19). However, the relationships between airborne $P$. herbarum spore concentrations, environmental factors, and disease incidence in asparagus fields under no-till production have not been previously investigated. The objective of this study was to determine the influence of environmental conditions on airborne spore concentrations and severity of purple spot of asparagus spears and ferns. This information may be used to guide spear harvests and to determine if modifications should be considered to improve or simplify TOM-CAST.

\section{MATERIALS AND METHODS}

Spore sampling. Airborne $P$. herbarum spore concentrations were monitored continuously from 22 April to 1 September 1992 (134 days), from 22 April to 15 September 1993 (147 days), and from 6 May 
to 16 September 1994 (134 days) in two no-till asparagus (cv. Viking) fields. Plots were $9 \times 22 \mathrm{~m}$ within the 2.0-ha Michigan Asparagus Research Farm (research farm) in Oceana County, MI and a 8.1-ha commercial grower's farm (commercial farm) in Oceana County, MI. The field at the research farm had been in production for approximately 3 to 4 years, and the commercial field was $>8$ years old. Both the field at the research farm and the commercial farm were on well-drained sandy soils (Benona sand and Spinks loamy sand, respectively). Crowns were spaced $23 \mathrm{~cm}$ apart within the rows, and row spacing was $1.5 \mathrm{~m}$. Plots were divided into 12 locations. No fungicides were applied to the plots, but fungicides were applied to asparagus adjacent to the plots according to commercial recommendations.

Airborne concentrations of $P$. herbarum ascospores and conidia were determined using a Burkard 7-day volumetric spore sampler (Burkard Manufacturing Co. Ltd., Rickmansworth, Hertfordshire, UK). The sampling airflow rate was 10 liters/min and the sampler was set to allow free movement according to wind direction so that the orifice faced into the prevailing wind. Ascospores and conidia were impacted onto tapes coated with an adhesive mixture of petroleum jelly and paraffin (9:1, wt/wt) dissolved in sufficient toluene to result in a thick, liquid consistency. Tapes were removed weekly, cut into 48$\mathrm{mm}$ lengths, scored at hourly intervals, stained with aniline blue in lactic acid (28 $\mathrm{mg}$ of aniline blue, $20 \mathrm{ml}$ of distilled water, $10 \mathrm{mg}$ of glycerol, $10 \mathrm{ml}$ of $85 \%$ lactic acid), mounted on glass slides under $22 \times$ $50 \mathrm{~mm}$ coverslips, and sealed using Cytoseal (Richard-Allan Scientific, Kalamazoo, MI). Slides were scanned with a compound microscope, and ascospores and conidia were examined at $\times 400$ magnification, identified based on morphological characteristics $(6,31)$, and enumerated. Counts were converted to numbers of ascospores and conidia per cubic meter of air sampled per hour. At the research farm, spore counts were not available for the following times due to equipment malfunction: 1 May 19921100 to 1500 h, 27 July 19921000 to 2400 h, 28 July 1992 100 to 900 h, 30 April 1993100 to 900 h, and 31 August $19931100 \mathrm{~h}$ to 2 September 19931000 h. Conidia concentrations were not tabulated from 22 April 1992 to 2 July $1992900 \mathrm{~h}$ at the commercial farm. Daily and weekly spore concentrations were calculated as the sum of all spores captured per cubic meter of air during that day or week.

Collection of environmental and disease data. Hourly environmental data of rainfall $(\mathrm{mm})$ and relative humidity $(\%)$ were measured by a Neogen Envirocaster (Neogen Co., Lansing, MI), and hourly temperature $\left({ }^{\circ} \mathrm{C}\right)$ and leaf wetness were measured by a digital recorder (Omnidata
DP223, Omnidata International Inc., Logan, UT) in each field. The leaf wetness sensor was an electrical impedance grid type and was located in the upper $75 \%$ of the crop canopy in the center of the bed at a $45^{\circ}$ angle facing north. Neogen Envirocaster data for temperature and leaf wetness were used when data from the Omnidata recorder were not available due to equipment malfunction (commercial farm: 15 September $19931500 \mathrm{~h}$ and 16 September 1994900 to $1200 \mathrm{~h}$; research farm: 2 May 19921800 h, 4 May 19922000 h, 12 May 19921100 h, 7 June 19921900 h, 20 June 19922100 h, 23 June 19921000 h, 30 June 1992900 h, 14 June 1993400 h, 7 July 1993100 to 2300 h, 28 July 1993 1100 to $1200 \mathrm{~h}$ ). Vapor pressure deficit (millibars) was calculated for both sites using temperature and relative humidity data (24). Daily and weekly means were calculated for temperature and vapor pressure deficit, and daily and weekly totals were calculated for rainfall and the number of hours of leaf wetness. Leaf wetness data were converted to the proportion of the day or week with leaf wetness.

Spears were harvested every 1 to 7 days according to normal production practices from early May until late June at both sites every year. Between 14 and 19 harvests were completed at each farm during the harvest season each year. A minimum of 100 spears from each harvest were chosen arbitrarily and evaluated for purple spot lesions. Disease incidence for each harvest was calculated as the percentage of spears with purple spot lesions out of the total number of spears evaluated. Fern lesions were enumerated following the last spear harvest (late June to mid-July), when the plants had produced secondary branches and cladophylls were beginning to emerge. Lesions on the main stems and secondary branches and cladophylls of four ferns adjacent to each other in the center of each of the 12 locations within each plot were counted every 6 to 8 days until midSeptember. This resulted in 8 evaluations in 1992,10 or 11 evaluations in 1993, and 12 evaluations in 1994 at each site.

Statistical analyses. Statistical analyses were performed using the SAS statistical package version 9.1 (SAS Institute, Inc., Cary, NC). Daily temporal trends in hourly conidia concentrations were identified using PROC LOESS, a nonparametric method for estimating local regression surfaces (5). The PROC CORR procedure of SAS was used to examine correlations between daily ascospore concentrations and average temperature, average vapor pressure deficit, leaf wetness (proportion of day wet), and total rainfall for each siteyear. Daily conidia concentrations were correlated with environmental factors for the same day and for the same day in combination with days prior to conidia capture (up to 4 days before). Regression analyses were performed for each site-year using
PROC ARIMA, regressing the daily total spore concentrations on the daily environmental factors assuming an autoregressive moving average (ARMA) error structure (4) when necessary. The mean was subtracted from each time series, and they were checked for stationarity. Differencing was completed for nonstationary series prior to analysis. Models were selected using Akaike information criterion (1) to measure goodness of fit. Lags of up to 4 days prior were allowed for each environmental factor for ARIMA models relating environmental factors with conidia concentrations to allow for the influences of environment on pathogen sporulation in the days prior to conidia capture. The PROC CORR procedure of SAS was used to conduct Pearson's correlation test to examine the correlations between purple spot incidence on asparagus spears and the total concentration of ascospores, average temperature, total rainfall, average vapor pressure deficit, and leaf wetness (proportion of day wet) for the day of and 2 days prior to harvest. The PROC MIXED procedure of SAS was used to determine the effects of weekly averages/sums for environmental factors and spore concentrations on disease development using a repeated measures design. The number of new lesions/fern were determined by simple subtraction. The number of new lesions/fern were natural logarithm transformed for each site-year prior to analysis, which resulted in a normal distribution for the residuals. The week of rating was considered a random effect with an autoregressive (1) covariance structure, and each individual fern was the subject. Parameters with $P \leq 0.05$ were considered statistically significant.

\section{RESULTS}

The concentrations of airborne conidia showed a marked diurnal periodicity with the highest concentrations between 700 and $1300 \mathrm{~h}$ and a peak at 2900 or $1000 \mathrm{~h}$. Lowest conidia concentrations occurred in the evening and in the dark, between 1600 and $600 \mathrm{~h}$ (Fig. 1). A daily periodicity was also noted for average vapor pressure deficit and leaf wetness (proportion wet) at both sites, but was not noted for rainfall or for ascospore concentrations (data not shown).

At the research farm, 2,404, 1,547, and 1,052 ascospores were sampled over the course of the sampling season in 1992, 1993, and 1994, respectively. More ascospores were trapped at the commercial farm than at the research farm in 1992, 1993, and 1994, with respective totals of $5,636,5,263$, and 1,512 ascospores trapped (Fig. 2). Between 47 and $61 \%$ of the total seasonal ascospores at the research farm, and between 58 and $68 \%$ of the total seasonal ascospores at the commercial farm were caught before the end of the harvest season in each of the 3 years monitored. In 
general, more ascospores were caught during the phase of spear growth (Fig. 2), and more conidia were caught during the fern growth stage (Fig. 3).

In correlation analyses between daily ascospore concentrations and environmental factors, rainfall was positively related to ascospore concentrations for four of the six site-years (Table 1). Vapor pressure deficit was negatively correlated with ascospore concentrations for four of the site-years. The period of leaf wetness was positively correlated with ascospore concentrations for three site-years. Temperature was not significantly correlated with ascospore concentrations for any of the site-years in this study. None of the envi- ronmental factors were significantly correlated with ascospore concentrations at the research farm in 1992 (Table 1). To further explore the relationships potentially suggested by correlation analysis, ARIMA models were developed to relate daily ascospore concentrations with environmental factors from the same day or from up to 4 days prior (Table 2). Only the models for the research farm in 1993 and 1994 required an autoregressive moving average error structure. The ARIMA models contained all of the environmental factors monitored for at least one site-year. A single equation modeling airborne ascospore concentrations in relation to environmental factors at all the locations was not apparent. However, rain was positively related and vapor pressure deficit was negatively related to concentrations at several site-years (Table 2).

Disease incidence on harvested spears varied over the course of the harvest season and from year to year. No clear seasonal patterns were observed for disease incidence on harvested spears at either site (Fig. 2). In 1992, incidence of purple spot on spears was lowest, with $\leq 38$ or $48 \%$ of spears exhibiting lesions at the research farm and commercial farm, respectively, over the course of the season. Relatively few harvests contained diseased spears in 1992 at either site. Both sites received the least amount of seasonal rainfall in 1992
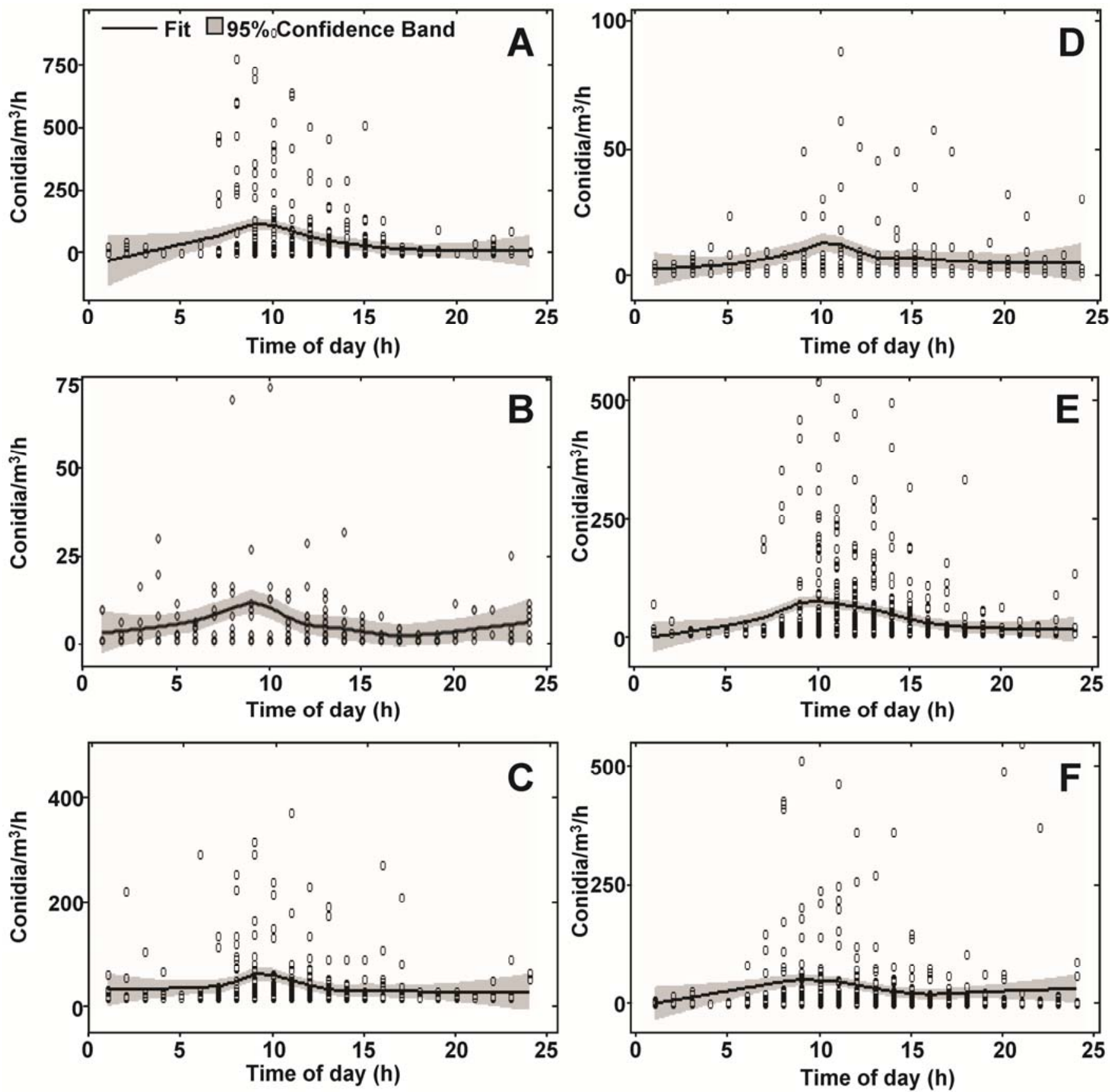

Fig. 1. Daily Pleospora herbarum conidia concentrations fit with a loess nonparametric regression curve (fit) at the commercial farm in A, 1992, B, 1993, and C, 1994 and at the research farm in D, 1992, E, 1993, and F, 1994. Note differences in the y axes. 

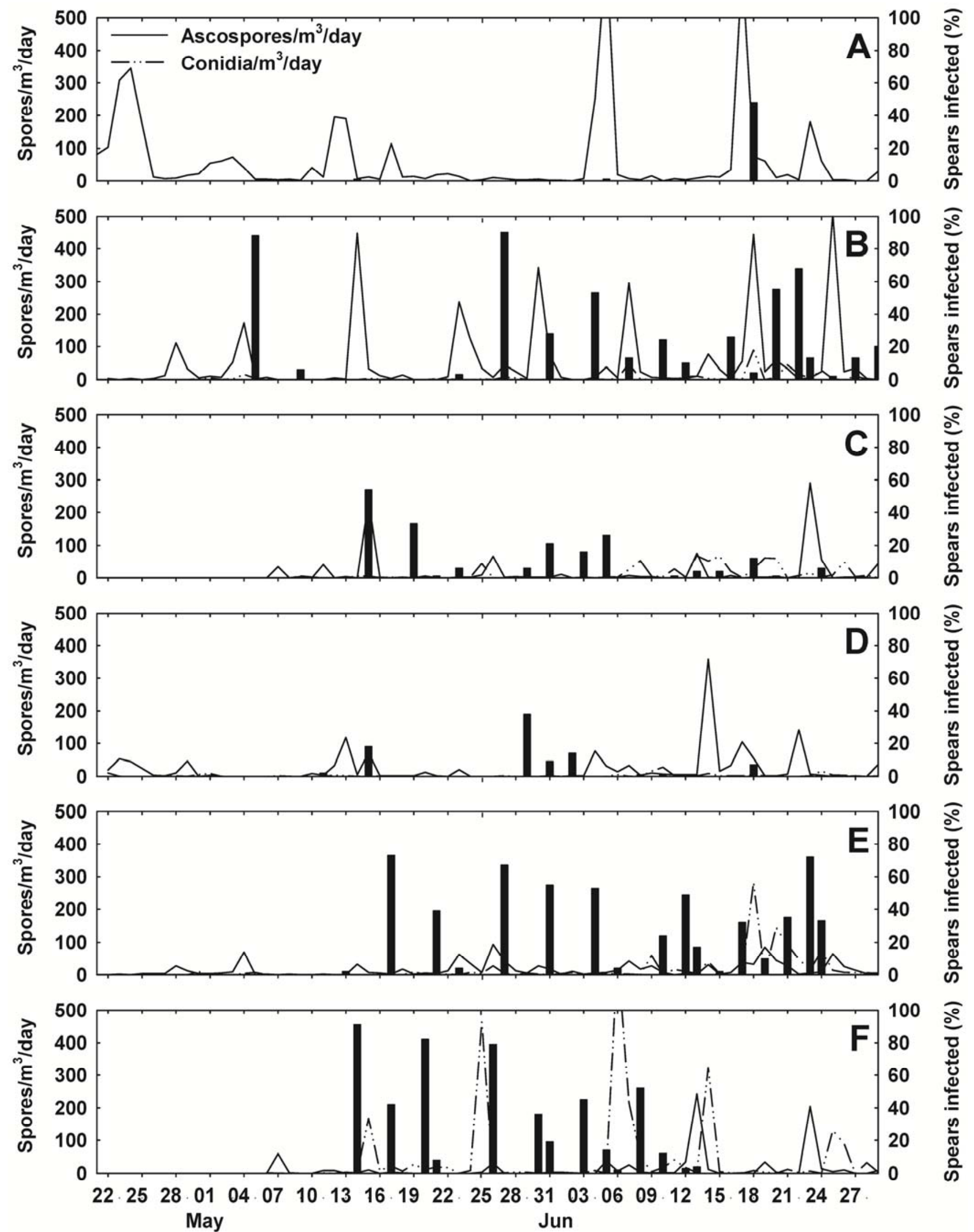

Fig. 2. Incidence of asparagus spears with purple spot lesions (\%) at each harvest (bars) in relation to daily airborne Pleospora herbarum ascospore and conidia concentrations (spores/m³/day) at the commercial farm in A, 1992, B, 1993, and C, 1994 and at the research farm in D, $1992, \mathbf{E}, 1993$, and F, 1994. 
and the greatest amount in 1993 (data not shown). In 1993, the greatest number of harvests with diseased spears were noted for both sites. As many as $90 \%$ of the spears in a single harvest at the commercial farm and $73 \%$ of the harvested spears at the research farm displayed purple spot lesions in 1993 (Fig. 2). In 1994, disease on the harvested spears was more severe and more frequent at the research farm as compared with the commercial farm. As many $91 \%$ of spears in a single harvest at
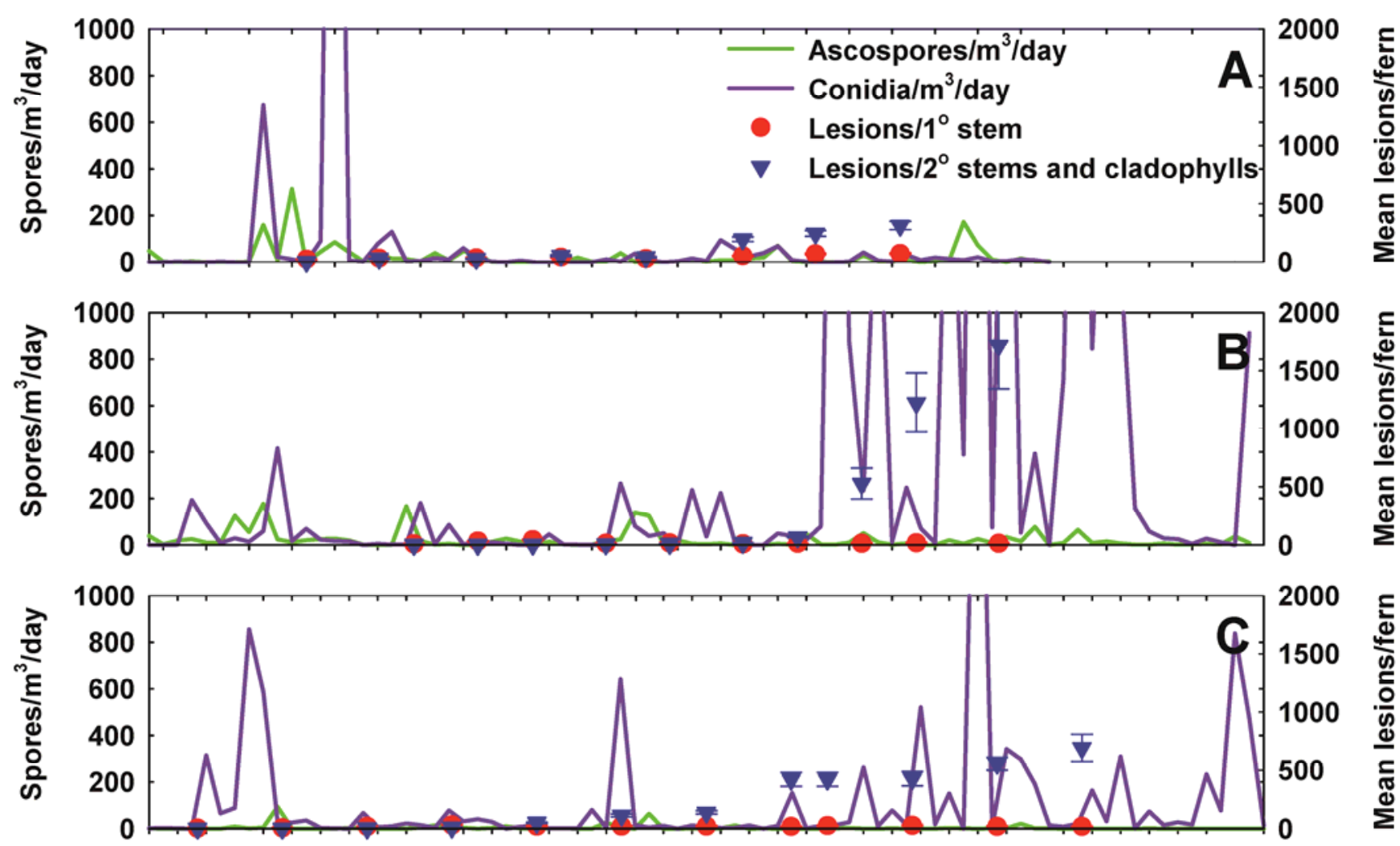

2000

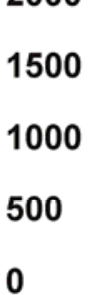

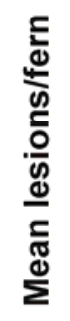

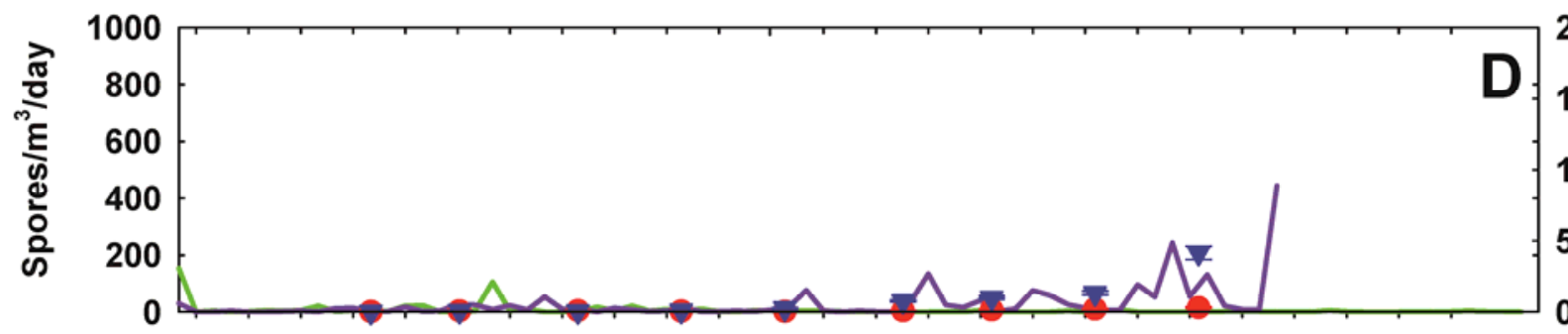

2000

1500

1000

500

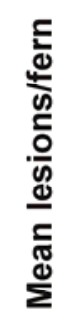
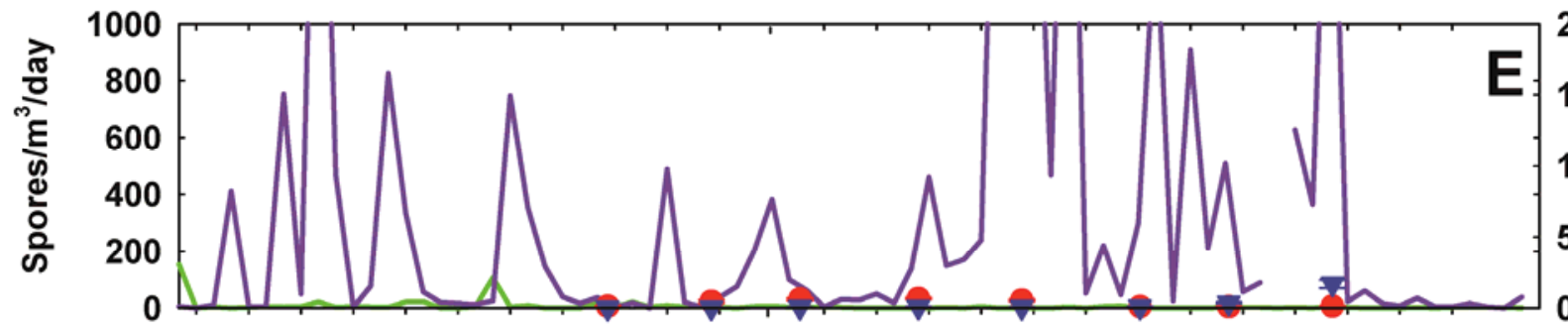

2000

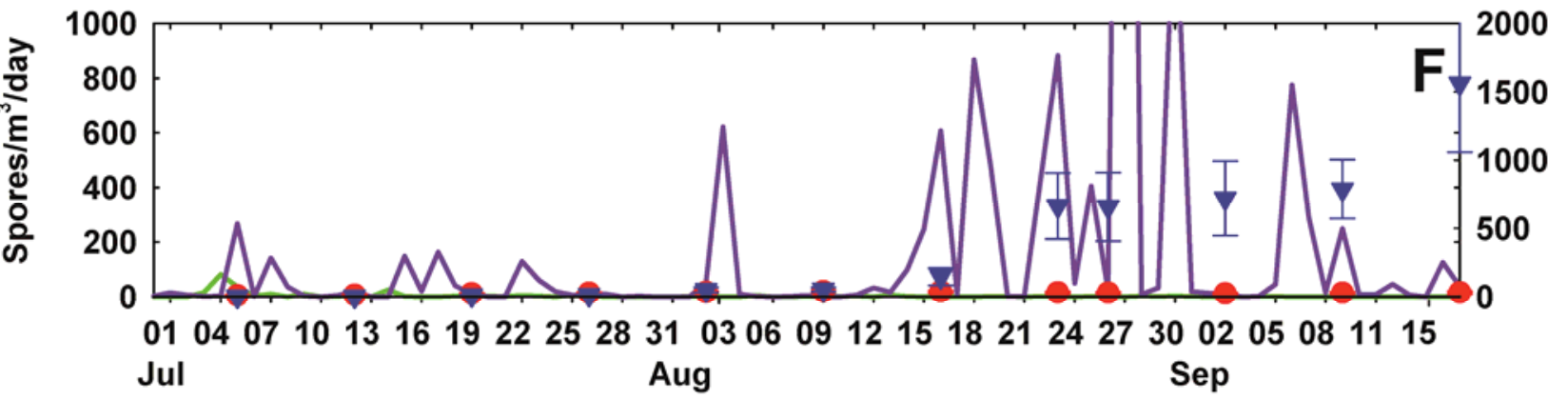

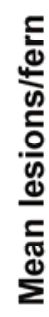

Fig. 3. Mean lesions/fern on primary $\left(1^{\circ}\right)$ and secondary $\left(2^{\circ}\right)$ stems and cladophylls each week in relation to daily airborne Pleospora herbarum ascospore and conidia concentrations (spores/m³/day) at the commercial farm in A, 1992, B, 1993, and C, 1994 and at the research farm in D, 1992, E, 1993, and F, 1994. Error bars represent standard error. 
the research farm and $54 \%$ of spears in a single harvest at the commercial farm were diseased (Fig. 2).

The environmental factors correlated with disease incidence on harvested spears differed for each site-year. Temperature was negatively correlated with disease incidence of harvested spears for the research farm in 1992 and 1994. Vapor pressure deficit was negatively correlated at the commercial farm in 1993 and the research farm in 1994. Rain and airborne ascospore concentrations were correlated with spear disease incidence at the commercial farm in 1992 (Table 3). Hence, temperature and vapor pressure deficit are negatively correlated and rain is positively correlated with disease on the spears. No correlations were observed between environmental factors for the day of and 2 days before harvest

Table 1. Correlations $(r)$ between daily total ascospore concentrations and daily total or average corresponding environmental factors at the commercial or research farm ${ }^{\mathrm{a}}$

\begin{tabular}{|c|c|c|c|c|c|c|}
\hline \multirow{2}{*}{$\begin{array}{l}\text { Environmental } \\
\text { factors }\end{array}$} & \multicolumn{3}{|c|}{ Commercial farm } & \multicolumn{3}{|c|}{ Research farm } \\
\hline & 1992 & 1993 & 1994 & 1992 & 1993 & 1994 \\
\hline \multicolumn{7}{|l|}{ Temp $^{\mathrm{b}}$} \\
\hline$V_{P D}^{c}$ & $-0.23 * *$ & $-0.31 * * *$ & $-0.32 * * *$ & & $-0.17 *$ & \\
\hline $\mathrm{LW}^{\mathrm{d}}$ & $0.28 * *$ & $0.34 * * *$ & & & & $0.24 * *$ \\
\hline Rain $^{\mathrm{e}}$ & $0.67 * * *$ & $0.37 * * *$ & & & $0.31 * * *$ & $0.41 * * *$ \\
\hline \multirow{2}{*}{\multicolumn{7}{|c|}{$\begin{array}{l}\text { at significant }=\text { blank column, } *=\text { significant at } P=0.05, * *=\text { significant at } P=0.01 \text {, and } * * * \\
\text { significant at } P=0.001 .\end{array}$}} \\
\hline & & & & & & \\
\hline \multicolumn{7}{|c|}{${ }^{\mathrm{b}}$ Temp $=$ average temperature $\left({ }^{\circ} \mathrm{C}\right)$} \\
\hline \multicolumn{7}{|c|}{ c VPD = average vapor pressure deficit. } \\
\hline \multicolumn{7}{|c|}{ d LW = leaf wetness (proportion). } \\
\hline e Rain $=$ total rai & all (mm). & & & & & \\
\hline
\end{tabular}

Table 2. ARIMA models relating daily ascospore concentrations at day t with environmental factors for the day of and a lag of up to 4 days prior to ascospore sampling at the commercial or research farm

\begin{tabular}{|c|c|}
\hline Year & Model \\
\hline \multicolumn{2}{|c|}{ Commercial farm } \\
\hline 1992 & $\begin{array}{l}\text { Asc }_{t}{ }^{\mathrm{a}}=12.86 \mathrm{Rain}_{\mathrm{t}}^{\mathrm{b}} \\
\text { where Temp } \\
\text { c } \mathrm{VPD}^{\mathrm{d}} \text {, and } \mathrm{LW}^{\mathrm{e}} \text { had first order differencing prior to analysis }\end{array}$ \\
\hline 1993 & $\begin{array}{l}\text { Asc }_{t}=-12.06 \mathrm{VPD}_{t}-10.42 \mathrm{VPD}_{\mathrm{t}-1}+2.53 \mathrm{Rain}_{\mathrm{t}} \\
\text { where Temp had first order differencing prior to analysis }\end{array}$ \\
\hline 1994 & $\begin{array}{l}\mathrm{Asc}_{\mathrm{t}}=-8.80 \mathrm{VPD}_{\mathrm{t}}-7.35 \mathrm{VPD}_{\mathrm{t}-1} \\
\text { where VPD and Rain had first order differencing prior to analysis }\end{array}$ \\
\hline \multicolumn{2}{|c|}{ Research farm } \\
\hline 1992 & $\begin{array}{l}\text { Asc }_{t}=-3.74 \mathrm{VPD}_{t} \\
\text { where VPD had first order differencing prior to analysis }\end{array}$ \\
\hline 1993 & $\begin{array}{l}\text { Asc }_{t}=0.99 \operatorname{Rain}_{t}+Z_{t} \text {, where } Z_{t}=0.91 z_{t-1}+0.97 e_{t-1}{ }^{f} \\
\text { where VPD had first order differencing prior to analysis }\end{array}$ \\
\hline 1994 & $\begin{array}{l}\text { Asc }_{t}=0.40 \mathrm{Temp}_{\mathrm{t}}+0.10 \mathrm{Temp}_{\mathrm{t}-1}+0.10 \mathrm{Temp}_{\mathrm{t}-2}+0.10 \mathrm{Temp}_{\mathrm{t}-3}+0.10 \mathrm{Temp}_{\mathrm{t}-4} \\
-13.00 \mathrm{LW}_{\mathrm{t}}-9.26 \mathrm{LW}_{\mathrm{t}}+0.04 \text { Rain }_{\mathrm{t}}+\mathrm{Z}_{\mathrm{t}} \text {, where } \mathrm{Z}_{\mathrm{t}}=-0.87 \mathrm{z}_{\mathrm{t}-1}+0.87 \mathrm{e}_{\mathrm{t}-1} \\
\text { where VPD had first order differencing prior to analysis }\end{array}$ \\
\hline
\end{tabular}

${ }^{a} \mathrm{Asc}_{\mathrm{t}}=$ ascospores $/ \mathrm{m}^{3} /$ day at day $\mathrm{t}$.

${ }^{\mathrm{b}}$ Rain $=$ total rainfall $(\mathrm{mm})$.

${ }^{\text {c }}$ Temp $=$ average temperature $\left({ }^{\circ} \mathrm{C}\right)$.

${ }^{\mathrm{d}} \mathrm{VPD}=$ average vapor pressure deficit.

${ }^{\mathrm{e}} \mathrm{LW}=$ leaf wetness (proportion).

${ }^{\mathrm{f}} \mathrm{Z}_{\mathrm{t}}=$ moving average part of the error, $\mathrm{e}_{\mathrm{t}}=$ autoregressive part of the error.

Table 3. Correlations $(r)$ between disease incidence on harvested spears and environmental factors and spore concentrations for the day of plus 2 days prior to harvest at the commercial or research farm ${ }^{\mathrm{a}}$

\begin{tabular}{|c|c|c|c|c|c|c|}
\hline \multirow{2}{*}{$\begin{array}{l}\text { Environmental } \\
\text { factors and spores }\end{array}$} & \multicolumn{3}{|c|}{ Commercial farm } & \multicolumn{3}{|c|}{ Research farm } \\
\hline & 1992 & 1993 & 1994 & 1992 & 1993 & 1994 \\
\hline Temp ${ }^{b}$ & & & & $-0.75^{* *}$ & & $-0.64 *$ \\
\hline $\mathrm{VPD}^{\mathrm{c}}$ & & $-0.58 * *$ & & & & $-0.61 *$ \\
\hline $\mathrm{LW}^{\mathrm{d}}$ & & & & & & \\
\hline Raine & $0.78 * * *$ & & & & & \\
\hline $\operatorname{Asc}^{\mathrm{f}}$ & $0.56^{*}$ & & & & & \\
\hline $\mathrm{Con}^{\mathrm{g}}$ & & & & & & \\
\hline
\end{tabular}

a Not significant $=$ blank column, $*=$ significant at $P=0.05, * *=$ significant at $P=0.01$, and $* * *=$ significant at $P=0.001$.

b $\mathrm{Temp}=$ average temperature $\left({ }^{\circ} \mathrm{C}\right)$.

${ }^{c} \mathrm{VPD}=$ average vapor pressure deficit.

${ }^{\mathrm{d}} \mathrm{LW}=$ leaf wetness (proportion).

${ }^{\mathrm{e}}$ Rain $=$ total rainfall $(\mathrm{mm})$.

${ }^{\mathrm{f}}$ Asc $=$ total ascospores $\left(\right.$ ascospores $\left./ \mathrm{m}^{3}\right)$.

g $\mathrm{Con}=$ total conidia $\left(\right.$ conidia $\left./ \mathrm{m}^{3}\right)$.

and disease incidence on harvested spears for the commercial farm in 1994 and the research farm in 1993.

At the research farm, 2,045, 26,396, and 16,494 conidia $/ \mathrm{m}^{3}$ were trapped over the course of the sampling period in 1992, 1993, and 1994, respectively. The number of conidia trapped over the course of the season was greater at the commercial farm than at the research farm in 1992 and 1993 , with 5,607 and 29,070 conidia $/ \mathrm{m}^{3}$ trapped, respectively, but not in 1994 when 15,196 conidia $/ \mathrm{m}^{3}$ were trapped. Between 89 and $98 \%$ of conidia were trapped at the research farm after the harvest season for the 3 years of sampling, and between 78 and $99 \%$ of conidia were sampled at the commercial farm after harvest in 1993 and 1994. Calculations were not completed for 1992 at the commercial farm, as conidia counts were only available for the period after the harvest season.

Correlations between airborne conidia concentrations and environmental factors were fairly consistent whether daily conidia concentrations were compared to the averages or sums of environmental factors for that same day or for the same day plus up to 4 days prior (Table 4). While no significant correlations were noted between conidia concentrations and environmental factors at the research farm in 1994, significant correlations were noted for the other five site-years. All of the environmental factors monitored were correlated with airborne conidia concentrations for at least one site-year at one of the lags selected. Airborne conidia concentrations were positively correlated with temperature and leaf wetness and negatively correlated with vapor pressure deficit for the same day. When environmental factors from the previous day were combined with environmental factors from the same day, temperature and leaf wetness were positively correlated and vapor pressure deficit was negatively correlated; rainfall was also positively correlated with conidia concentrations for some of the site-years (Table 4). The results of these analyses suggest that temperature, vapor pressure deficit, leaf wetness, and rainfall in the days leading up to conidia release to the air may affect airborne conidia concentrations. ARIMA models were generated to further explore the relationships between conidia concentrations and environmental factors on the same day or for lags up to 4 days prior. While leaf wetness and rainfall were the most important factors to explain airborne conidia concentrations for both sites, the relationships between these factors and airborne conidial concentration were not clear, as different results were produced depending on the site-year (Table 5).

Disease severity on the fern varied from year to year, with fewer lesions on ferns at both sites in 1992 compared to other years monitored (Fig. 3). Most of the lesions on ferns were observed on the secondary 
branches and cladophylls, and the number of lesions increased throughout the growing season (Fig. 3). Linear mixed models were developed for each site-year to relate environmental conditions in the week prior to disease evaluation with the number of new lesions on the fern. New lesions on the ferns were positively related with leaf wetness and negatively related with temperature, vapor pressure deficit, and rainfall in the week prior to disease assessment at several of the site-years monitored. Leaf wetness, vapor pressure deficit, and rainfall were included in $\geq 4$ models. Leaf wetness had a positive slope in three of four models, vapor pressure deficit had a negative slope in three of four models, and rainfall had a negative slope in five of six models. The role of temperature is more ambiguous, as it had a negative slope in three models and a positive slope in two models (Table 6). There appeared to be some observable association between new lesions on the ferns and weeks with higher airborne conidia concentrations (Fig. 3B to $\mathrm{D}$ and $\mathrm{F}$ ).

\section{DISCUSSION}

Ascospores appeared to be the inoculum primarily responsible for initiating purple spot disease on spears during the early harvest period. Most asparagus growers in Michigan produce asparagus for both the fresh market and the processing market. Being able to predict the environmental conditions conducive for ascospore release to the air and for subsequent purple spot lesion development on spears is desirable, as spears with lesions may be rejected for the fresh market. Asparagus growers could use this information to direct harvests following weather favorable for purple spot development to the processing market, where blemishes on spears are better tolerated. Average temperature and vapor pressure deficit were negatively related and rainfall was positively related with disease on spears. The negative relationship with temperature may be due to the fact that asparagus spears grow more slowly and are thus exposed to inoculum longer when temperatures are cooler. A previous study found that purple spot on asparagus spears was more severe following rainfall or overhead irrigation (10). While our study also found that high rainfall was favorable for purple spot on asparagus spears, periods of low vapor pressure deficit were also favorable for disease development. A previous study found that longer periods of wetness were conducive for infection on garlic and onion following inoculation with $P$. allii ascospores (3).

Daily ascospore concentrations were positively correlated with rainfall and leaf wetness, and negatively correlated with vapor pressure deficit at both fields monitored. ARIMA models follow previous observations for Pleospora allii that found ascospore concentrations to be associated with increased rainfall and low vapor pressure deficit (27). The positive relationship between rainfall and airborne ascospore concentrations is also consistent with previous experiments that showed $P$. herbarum pseudothecia require free water to discharge ascospores (2). A daily periodicity for airborne ascospore concentrations was not observed in our research, which agrees with previous sampling of $P$. allii ascospores $(27,30)$.

Airborne conidia were detected as early as mid-May, but most $(>78 \%)$ conidia were sampled after the spear harvest sea- son during the time when spears develop into ferns. Concentrations of airborne conidia in our study displayed a diurnal periodicity, with most of the spores sampled between mid-morning and early afternoon, which agrees with what has been observed previously in asparagus (20) and for $P$. allii in pear and garlic crops $(27,30,32)$.

Leaf wetness and temperature were positively related and vapor pressure deficit was negatively related to airborne conidia concentrations at both of the fields monitored in this research. Rainfall on the same day was not significantly related to

Table 4. Correlations $(r)$ between daily conidia concentrations and environmental factors for the day of and up to 4 days prior ( $-\mathrm{X}$ days) to conidia sampling at the commercial or research farm ${ }^{\mathrm{a}}$

\begin{tabular}{|c|c|c|c|c|c|c|}
\hline \multirow{2}{*}{$\begin{array}{l}\text { Environmental } \\
\text { factors }\end{array}$} & \multicolumn{3}{|c|}{ Commercial farm } & \multicolumn{3}{|c|}{ Research farm } \\
\hline & 1992 & 1993 & 1994 & 1992 & 1993 & 1994 \\
\hline $\begin{array}{l}\text { Temp } \\
\text { VPD }^{\mathrm{c}} \\
\text { LW }^{\mathrm{d}} \\
\text { Rain }\end{array}$ & & & $0.21 *$ & $\begin{array}{l}-0.28 * * \\
0.39 * * *\end{array}$ & $\begin{array}{l}0.29 * * * \\
0.26 * *\end{array}$ & \\
\hline $\begin{array}{l}\text { Temp (-1) } \\
\text { VPD (-1) } \\
\text { LW (-1) } \\
\text { Rain (-1) }\end{array}$ & $0.38^{* * *}$ & $\begin{array}{l}0.18^{*} \\
0.20^{*}\end{array}$ & $\begin{array}{l}0.22^{*} \\
0.23^{*}\end{array}$ & $\begin{array}{l}-0.25^{* *} \\
0.40^{* * *}\end{array}$ & $\begin{array}{c}0.31 * * * \\
-0.17 * \\
0.32 * * *\end{array}$ & \\
\hline $\begin{array}{l}\text { Temp (-2) } \\
\text { VPD (-2) } \\
\text { LW (-2) } \\
\text { Rain }(-2)\end{array}$ & $0.44 * * *$ & $\begin{array}{l}0.19^{*} \\
0.21^{*}\end{array}$ & $0.23 * *$ & \begin{tabular}{c}
\multicolumn{1}{c}{$0.21^{*}$} \\
$-0.23^{*}$ \\
$0.50^{*} * *$
\end{tabular} & $\begin{array}{l}0.33^{* * *} \\
0.30^{* * *}\end{array}$ & \\
\hline $\begin{array}{l}\text { Temp (-3) } \\
\text { VPD (-3) } \\
\text { LW (-3) } \\
\text { Rain }(-3)\end{array}$ & $0.39 * *$ & $\begin{array}{r}0.21^{*} \\
-0.17 *\end{array}$ & $0.22 *$ & $\begin{array}{l}-0.22^{*} \\
0.48^{* * *}\end{array}$ & $\begin{array}{l}0.35 * * * \\
0.29 * * *\end{array}$ & \\
\hline $\begin{array}{l}\text { Temp (-4) } \\
\text { VPD (-4) } \\
\text { LW (-4) } \\
\text { Rain }(-4)\end{array}$ & $0.36 * *$ & $\begin{array}{l}0.21^{*} \\
0.23^{* *}\end{array}$ & $0.20 *$ & $\begin{array}{l}-0.22^{*} \\
0.47 * * *\end{array}$ & $\begin{array}{l}0.36^{* * * *} \\
0.26^{* *}\end{array}$ & \\
\hline
\end{tabular}

a Not significant $=$ blank column, $*=$ significant at $P=0.05, * *=$ significant at $P=0.01$, and $* * *=$ significant at $P=0.001$.

${ }^{\text {b }}$ Temp $=$ average temperature $\left({ }^{\circ} \mathrm{C}\right)$.

${ }^{c} \mathrm{VPD}=$ average vapor pressure deficit.

${ }^{\mathrm{d}} \mathrm{LW}=$ leaf wetness (proportion).

${ }^{\mathrm{e}}$ Rain $=$ total rainfall $(\mathrm{mm})$.

Table 5. ARIMA models relating daily conidia concentrations at day $t$ with environmental factors for the day of and a lag of up to 4 days prior to conidia sampling at the commercial or research farm

\begin{tabular}{|c|c|}
\hline Year & Model \\
\hline \multicolumn{2}{|c|}{ Commercial farm } \\
\hline 1992 & $\begin{array}{l}\mathrm{Con}_{\mathrm{t}}^{\mathrm{a}}=-30.59 \mathrm{LW}_{\mathrm{t}}+10.99 \mathrm{Rain}_{\mathrm{t}}-23.97 \operatorname{Rain}_{\mathrm{t}-1}^{\mathrm{b}} \\
\text { where Temp } \\
\text { c VPD }\end{array}$ \\
\hline 1993 & $\begin{array}{l}\mathrm{Con}_{t}=67.13 \mathrm{LW}_{\mathrm{t}}-17.24 \mathrm{Rain}_{\mathrm{t}} \\
\text { where Temp had first order differencing prior to analysis }\end{array}$ \\
\hline 1994 & $\begin{array}{l}\mathrm{Con}_{t}=1.18 \mathrm{Rain}_{t}-9.77 \mathrm{Rain}_{\mathrm{t}-1} \\
\text { where Temp had first order differencing prior to analysis }\end{array}$ \\
\hline \multicolumn{2}{|c|}{ Research farm } \\
\hline 1992 & $\begin{array}{l}\mathrm{Con}_{t}=6.91 \mathrm{LW}_{\mathrm{t}} \\
\text { where VPD and Rain had first order differencing prior to analysis }\end{array}$ \\
\hline 1993 & $\begin{array}{l}\mathrm{Con}_{\mathrm{t}}=21.13 \mathrm{LW}_{\mathrm{t}}-35.82 \mathrm{LW}_{\mathrm{t}-1}-13.61 \mathrm{Rain}_{\mathrm{t}}+\mathrm{Z}_{\mathrm{t}} \text {, } \\
\text { where } \mathrm{Z}_{\mathrm{t}}=0.18 \mathrm{e}_{\mathrm{t}-1}{ }^{\mathrm{f}}+0.38 \mathrm{e}_{\mathrm{t}-2} \text { where VPD had first order differencing prior to } \\
\text { analysis }\end{array}$ \\
\hline 1994 & $\begin{array}{l}\mathrm{Con}_{t}=-10.19 \mathrm{LW}_{\mathrm{t}}-113.56 \mathrm{LW}_{\mathrm{t}-1} \\
\text { where VPD had first order differencing prior to analysis }\end{array}$ \\
\hline
\end{tabular}

${ }^{a} \operatorname{Con}_{t}=$ conidia $/ \mathrm{m}^{3} /$ day at time $\mathrm{t}$.

${ }^{\mathrm{b}}$ Rain $=$ total rainfall $(\mathrm{mm})$.

${ }^{\mathrm{c}}$ Temp $=$ average temperature $\left({ }^{\circ} \mathrm{C}\right)$.

${ }^{\mathrm{d}} \mathrm{VPD}=$ average vapor pressure deficit.

${ }^{\mathrm{e}} \mathrm{LW}=$ leaf wetness (proportion).

${ }^{\mathrm{f}} \mathrm{e}_{\mathrm{t}}=$ the autoregressive error. 
Table 6. Linear mixed models relating the number of new lesions on asparagus ferns to environmental factors in the week prior to disease evaluation

\begin{tabular}{ll}
\hline Year & Model \\
\hline Commercial farm & \\
1992 & $\ln (\text { fern })^{\mathrm{a}}=9.49-0.46 \mathrm{Temp}^{\mathrm{b}}+4.0 \mathrm{LW}^{\mathrm{c}}-0.02 \mathrm{Rain}^{\mathrm{d}}$ \\
1993 & $\ln ($ fern $)=-3.02-0.74 \mathrm{Temp}+0.76 \mathrm{VPD}^{\mathrm{e}}+34.64 \mathrm{LW}+0.20 \mathrm{Rain}$ \\
1994 & $\ln ($ fern $)=6.67-0.66 \mathrm{VPD}-0.03 \mathrm{Rain}$ \\
Research farm & \\
1992 & $\ln ($ fern $)=-2.84+0.49 \mathrm{Temp}-0.76 \mathrm{VPD}+4.49 \mathrm{LW}-0.03$ Rain \\
1993 & $\ln ($ fern $)=5.71+0.33$ Temp $-1.10 \mathrm{VPD}-7.35 \mathrm{LW}-0.05$ Rain \\
1994 & $\ln ($ fern $)=7.98-0.16 \mathrm{Temp}-0.09$ Rain
\end{tabular}

a $\ln ($ fern $)=$ natural logarithm(mean number of new lesions/fern/week +1$)$.

b Temp $=$ average temperature $\left({ }^{\circ} \mathrm{C}\right)$.

${ }^{c}$ LW = leaf wetness (proportion).

${ }^{\mathrm{d}}$ Rain $=$ total rainfall $(\mathrm{mm})$.

e VPD = average vapor pressure deficit.

conidia concentrations at either site. When environmental factors for the days prior to conidia capture were examined for correlations with airborne conidia concentrations, average temperature, total leaf wetness, and total rainfall were positively correlated and vapor pressure deficit was negatively correlated with airborne conidia concentrations. Previous research with $P$. allii in garlic found airborne concentrations of conidia were correlated with rainy days, high relative humidity, and moderate temperatures (12 to $21^{\circ} \mathrm{C}$ ) in the days prior to conidia capture (26). $P$. allii conidia from pear orchards were previously described as positively correlated with the duration of leaf wetness, negatively correlated with vapor pressure deficit, and were not correlated with total rainfall or with rainy days (30).

Disease severity on ferns, measured as the weekly number of new lesions, was positively related to leaf wetness, and negatively related to temperature, vapor pressure deficit, and rainfall the week prior to disease assessment at $\geq 50 \%$ of the site-years monitored. A previous study with $P$. allii showed that conidia required a film of water on the surface of pear leaves to infect (17), and increased disease levels were observed on asparagus ferns subjected to longer periods of misting with water (15) after inoculation with $P$. herbarum conidia. Longer periods of wetness also increased disease severity in pear exposed to $P$. allii conidia (22). Leaf wetness appeared to be the most important environmental factor influencing disease development on the fern, but temperature, vapor pressure deficit, and rainfall also appeared significant in this study. The results of this study do not suggest that simplification of TOM-CAST to include fewer factors is warranted, but the addition of rainfall to the model may be helpful.

\section{ACKNOWLEDGMENTS}

This material is based upon work supported by Michigan Asparagus Research, Inc. We thank J.
Byrne for assistance in disease assessment, W. Wang for help with the statistical analysis, and L. Quesada-Ocampo for critical review of the manuscript.

\section{LITERATURE CITED}

1. Akaike, H. 1974. A new look at the statistical model identification. IEEE T. Automat. Contr. 19:716-723. spore discharge. Mycologia 11:125-128.

3. Basallote-Ureba, M. J., Prados-Ligero, A. M., and Melero-Vara, J. M. 1999. Aetiology of leaf spot of garlic and onion caused by Stemphylium vesicarium in Spain. Plant Pathol. 48:139-145.

4. Box, G. E. P., and Tiao, G. C. 1975. Intervention analysis with applications to economic and environmental problems. J. Am. Stat. Assoc. 70:70-79.

5. Cleveland, W. S. 1979. Robust locallyweighted regression and smoothing scatterplots. J. Am. Stat. Assoc. 74:829-836.

6. Ellis, M. B. 1971. Dematiaceous hyphomycetes. Commonwealth Mycological Institute, Kew, England.

7. Elmer, W. H., Johnson, D. A., and Mink, G. I. 1996. Epidemiology and management of the diseases causal to asparagus decline. Plant Dis. 80:117-125.

8. Evans, T. A., and Stephens, C. T. 1984. First report in Michigan of the teleomorph of Stemphylium vesicarium, causal agent of purple spot of asparagus. Plant Dis. 68:1099.

9. Falloon, P. G. 1982. The need for asparagus breeding in New Zealand. N.Z. J. Exp. Agric. 10:101-109.

10. Falloon, P. G., Falloon, L. M., and Grogan, R. G. 1987. Etiology and epidemiology of Stemphylium leaf spot and purple spot of asparagus in California. Phytopathology 77:407-413.

11. Hausbeck, M. K., Cortright, B. D., Myers, N., and Olsen, L. G. 2008. Optimal use of fungicides to manage purple spot and rust on asparagus ferns. Acta Hortic. 776:153-160.

12. Hausbeck, M. K., Hartwell, J., and Byrne, J. M. 1999. Epidemiology of Stemphylium leaf spot and purple spot in no-till asparagus. Acta Hortic. 479:205-210.

13. Johnson, D. A. 1990. Effect of crop debris management on severity of Stemphylium purple spot of asparagus. Plant Dis. 74:413-415.

14. Johnson, D. A., and Lunden, J. D. 1984. First report of purple spot (Stemphylium vesicarium) of asparagus in Washington. Plant Dis. 68:1099.
2. Atanasoff, D. 1919. A novel method of asco-
15. Johnson, D. A., and Lunden, J. D. 1986. Effects of wounding and wetting duration on infection of asparagus by Stemphylium vesicarium. Plant Dis. 70:419-420.

16. Kelly, J. F., and Bai, Y. 1999. Pre-senescence removal of asparagus (Asparagus officinalis L.) fern. Acta Hortic. 479:427-430.

17. Llorente, I., and Montesinos, E. 2002. Effect of relative humidity and interrupted wetness periods on brown spot severity of pear caused by Stemphylium vesicarium. Phytopathology 92:99-104.

18. Madden, L., Pennypacker, S. P., and MacNab, A. A. 1978. FAST, a forecast system for Alternaria solani on tomato. Phytopathology 68:1354-1358.

19. Menzies, S. A., Bansal, R. K., and Broadhurst, P. G. 1991. Effect of environmental factors on severity of Stemphylium leaf spot on asparagus. N.Z. J. Crop Hortic. 19:135-141.

20. Menzies, S. A., Broadhurst, P. G., and Triggs, C. M. 1992. Stemphylium disease of asparagus (Asparagus officinalis L.) in New Zealand. N.Z. J. Crop Hortic. 20:427-433.

21. Meyer, M. P., Hausbeck, M. K., and Podolsky, R. 2000. Optimal fungicide management of purple spot of asparagus and impact on yield. Plant Dis. 84:525-530.

22. Montesinos, E., Moragrega, C., Llorente, I., Vilardell, P., Bonaterra, A., Ponti, I., Bugiani, R., Cavanni, P., and Brunelli, A. 1995. Development and evaluation of an infection model for Stemphylium vesicarium on pear based on temperature and wetness duration. Phytopathology 85:586-592.

23. Montesinos, E., and Vilardell, P. 1992. Evaluation of FAST as a forecasting system for scheduling fungicide sprays for control of Stemphylium vesicarium on pear. Plant Dis. 76:1221-1226.

24. Murray, F. W. 1967. On the computation of saturated vapor pressure. J. Appl. Meterol. 6:203-204.

25. Pitblado, R. E. 1992. The development and implementation of Tom-Cast. Ontario Ministry of Agriculture and Food, Ridgetown, Canada.

26. Prados-Ligero, A. M., Gonzalez-Andujar, J. L., Melero-Vara, J. M., and Basallote-Ureba, M. J. 1998. Development of Pleospora allii on garlic debris infected by Stemphylium vesicarium. Eur. J. Plant Pathol. 104:861-870.

27. Prados-Ligero, A. M., Melero-Vara, J. M., Corpas-Hervias, C., and Basallote-Ureba, M. J. 2003. Relationships between weather variables, airborne spore concentrations and severity of leaf blight of garlic caused by Stemphylium vesicarium in Spain. Eur. J. Plant Pathol. 109:301-310.

28. Pryor, B. M., and Gilbertson, R. L. 2000. Molecular phylogenetic relationships amongst Alternaria species and related fungi based upon analysis of nuclear ITS and mt SSU rDNA sequences. Mycol. Res. 104:1312-1321.

29. Putnam, A. R., and Lacy, M. L. 1977. Asparagus management with no-tillage. Michigan State Univ. Res. Rep. 339:11.

30. Rossi, V., Bugiani, R., Giosue, S., and Natali, P. 2005. Patterns of airborne conidia of Stemphylium vesicarium, the causal agent of brown spot disease of pears, in relation to weather conditions. Aerobiologia 21:203-216.

31. Simmons, E. G. 1969. Perfect states of Stemphylium. Mycologia 61:1-26.

32. Suheri, H., and Price, T. V. 2000. Stemphylium leaf blight of garlic (Allium sativum) in Australia. Australas. Plant Pathol. 29:192-199. 